\title{
A Collaborative Learning Approach to Dialogic Peer Feedback: A Theoretical Framework
}

\begin{abstract}
Feedback has a powerful influence on learning. However, feedback practices in higher education often fail to produce the expected impact on learning. This is mainly because of its implementation as a one-way transmission of diagnostic information where students play a passive role as the information receivers. Dialogue around feedback can enhance students' sense making from feedback and capacities to act on it. Yet, dialogic feedback has been mostly implemented as an instructor-led activity, which is hardly affordable in large classrooms. Dialogic peer feedback can offer a scalable solution; however, current practices lack a systematic design, resulting in low learning gains. Attending to this gap, this paper presents a theoretical framework that structures dialogic feedback as a three-phase collaborative activity, involving different levels of regulation: first, planning and coordination of feedback activities (involving socially shared regulation), second, feedback discussion to support its uptake (involving co-regulation), and last, translation of feedback into task engagement and progress (involving self-regulation). Based on the framework, design guidelines are provided to help practitioners shape their feedback practices. The application of the principles is illustrated through an example scenario. The framework holds a great potential to promote student-centred approaches to feedback practices in higher education.
\end{abstract}

\section{Introduction}

Feedback is a critical element of the learning process (Butler \& Winne, 1995; Hattie, 1999). Research consistently reports that good feedback can guide students' learning and lead to higher performance and achievement (Geitz et al., 2015). However, given the complex nature of feedback, its design and implementation often do not yield the promised learning opportunities in practice. Providing good feedback is itself a difficult task. As a result, feedback may often comprise some problems, such as the use of complex academic language (MacLellan, 2001), that impede its uptake by students. Even if the given feedback is considered good, its effective use by students is not guaranteed as many factors (e.g., perceptions, motivation, and ability) may affect the way it is approached, interpreted, and acted upon (Carless et al., 2011). These issues are accentuated specifically when feedback is practiced as one-way transmission of diagnostic information (Carless et al., 2011). Yet, feedback in higher education is usually designed as a transmission activity where feedback arrives during the final assessment of student work. Such feedback practices discard the dynamic nature of learning 
and optimistically assume that students by themselves understand and use the feedback for future tasks (Nicol \& Macfarlane-Dick, 2006; Carless, 2013).

Feedback as telling situates students as passive learners and lacks interactive processes such as negotiating meaning from feedback that can significantly enhance the learning gains (Stahl et al., 2006). Accordingly, students often face difficulties in translating feedback messages into clear learning strategies (Holmes \& Papageorgiou, 2009), and they demand for active learning opportunities (such as discussions) to interpret feedback interactively (Ellegaard et al., 2017). Dialogue can help students actively construct meaning from feedback and collectively decide on the learning actions to take to improve learning and task performance (Yang \& Carless, 2013). Empirical studies noted that dialogue can elevate the impact of feedback on learning and achievement (Bloxham \& Campbell, 2010; Nicol, 2010; Gikandi \& Morrow, 2015). However, the recent literature has focused on the scenarios where instructors take the leading role in building dialogue with students to discuss the (instructor) feedback (Ajjawi \& Boud, 2018). Instructor-centred dialogic feedback is unlikely given the heavy teaching workload in higher education where the class sizes are increasing every year (Nicol \& Macfarlane-Dick, 2006). One scalable approach in this regard could be dialogic peer feedback. Dialogic peer feedback can be defined as students' collaborative meaning-making about feedback by engaging in dialogue with their peers (providing the feedback) (Filius et al., 2018).

However, the way dialogic feedback is implemented with instructors may not work in the same way when students are in charge. Maintaining a productive dialogue around feedback can be challenging even for instructors (Steen-Utheim \& Wittek, 2017). Unsurprisingly, students may face obstacles during dialogic peer feedback without a systematic guidance and structure. Yet, existing practices of dialogic peer feedback have been limited in that they lack 
a systematic design approach and they optimistically rely on the potential emerging from students' dialogic interactions. We argue that this is partly because the conceptualization of dialogic peer feedback in the literature is poor. The literature is limited to the definition of dialogic feedback as a process where students simply engage in a dialogue with peers around the feedback provided (by the peers). To the best of our knowledge, there is no research work that frames dialogic peer feedback from a theoretical perspective with a detailed account and structure of dialogic feedback processes.

Attending to this gap, this paper presents a theoretical framework that considers peer feedback as a collaborative learning activity, in which feedback dialogue is structured in three distinct phases among peers. The framework also outlines the learning processes involved (in each of the phases), along with the roles that learners play in these processes. The proposed framework provides simple and flexible yet comprehensive and concrete representation of dialogic peer feedback and aims to guide practitioners when designing student-centred feedback practices. In the following sections, we first elaborate further on the need for framing dialogic peer feedback from a theoretical perspective, and then present the theoretical framework. Later, we propose guidelines for operationalizing the proposed framework to design and implement robust dialogic peer feedback practices. Next, we provide an example scenario to demonstrate the application of the design principles in practice. The paper concludes with discussion and suggestions for future work.

\section{Background}

\section{Feedback: From Telling towards Dialogue}

Feedback helps students clarify misconceptions, and identify flaws in their understanding and learning strategies in order to close the gap between current and desired performance (Sadler, 1989). However, feedback has limited impact on student learning in higher education (Urquhart 
et al., 2014). A large part of the problem lies in the fact that feedback is widely practiced as monologue, which discards the dynamic nature of learning (Nicol \& Macfarlane-Dick, 2006; Ajjawi \& Boud, 2017). That is, learners receiving the feedback are situated as listeners or readers who are optimistically assumed to understand the feedback received, and to interpret and act upon it (Nicol \& Macfarlane-Dick, 2006; Boud \& Molloy, 2016). Sutton and Gill (2010) use the analogy of "learning a new language" when describing the difficulty of decoding and understanding feedback messages. As a result, many students fail to make meaning of the feedback and use it to improve their learning (Holmes \& Papageorgiou, 2009).

In early 2000, Askew and Lodge (2000), criticizing the dominant stance in the literature that feedback is a gift given to students, proposed that feedback is a process in which students as active learners co-construct knowledge through dialogue (i.e., two-way 'ping-pong' interaction). This re-conceptualization of feedback within the socio-constructivist theory of learning has guided the research in the last years (Nicol, 2010; Carless et al., 2011). That is, the recent literature views feedback as a dialogic process that aims to develop students' capacity to monitor, evaluate, and regulate their learning through continuous and refined interactions with others (Nicol, 2010; Carless, 2016; Ajjawi \& Boud, 2018). In dialogic feedback, students are considered active learners who construct meaning and regulate their learning by engaging in fruitful social interactions with others (Orsmond et al., 2013; Ajjawi \& Boud, 2017).

Adhering to this change in the paradigm of feedback, the most recent theoretical models and frameworks have investigated dialogue as part of the feedback practice (Orsmond et al., 2013; O’Donovan et al., 2015). Yang and Carless (2013) proposed an architecture of dialogic feedback, consisting of three dimensions: cognitive, social-affective, and structural, along with their corresponding barriers (student-related barriers, teacher-related barriers, and institution- 
related barriers, respectively). These authors proposed six strategies to overcome the barriers associated with each dimension, and therefore to enhance dialogic feedback processes (Yang \& Carless, 2013). In a recent theoretical analysis of dialogic feedback, Steen-Utheim and Wittek (2017) operationalize four quality dimensions of dialogue: emotional and relational support, maintenance of dialogue, expressing themselves, and the other's contribution to individual growth. For each dimension, the authors discussed practical implications for teachers to facilitate dialogic feedback for supporting learning.

The fast advancing knowledge on enhancing and sustaining feedback dialogue is promising. However, so far, the literature focuses on scenarios where the instructors are assumed to actively engage in dialogue with students (Ajjawi \& Boud, 2018). This focus might be motivated by the fact that today's higher education practices are highly instructor-centred (Wright, 2011). Accordingly, targeting the instructors, the research has generated guidelines to sustain and enhance feedback dialogue (Ajjawi \& Boud, 2017; Steen-Utheim \& Wittek, 2017). However, the practice of dialogic feedback that increases the workload for instructors needs to be reconsidered in large-scale learning contexts. Initiating and continuing dialogue with every student and addressing their distinct learning needs is unfeasible for instructors who teach large enrolment classes. Thus, there is a need for new theoretical models of dialogic feedback that are student-centred and that can scale to large learning populations in higher education.

\section{The Need for Framing Dialogic Peer Feedback}

There are two main drivers for this paper to focus on peers (rather than instructors) to implement dialogic feedback. The first motivation is rooted in the practical constraints in higher education. Instructors' workload is increasing in parallel to growing class sizes and severe budget cuts in higher education (Shi, 2019). Instructor-led dialogic feedback unquestionably has such advantages as high quality of advising (Hamer et al., 2015); however, 
it might be very demanding for the instructors who are teaching to large learning cohorts. Providing feedback and maintaining dialogue with every student in large classrooms is unaffordable (Nicol \& Macfarlane-Dick, 2006). In this regard, we suggest that the existence of a high number of students can be exploited to scale dialogic feedback without adding more to instructors' ever-increasing teaching workload.

The second motivation is regarding the distinct learning benefits offered by peer feedback that are not attainable through instructor feedback (Geitz et al., 2015). These benefits can be enhanced if students engage in dialogue around feedback with the peers (Ertmer et al., 2007). Students attend to the feedback from peers more profoundly since they view the peers as non-experts on the topic with equal status (Geitz et al., 2015). Filius and his colleagues (Filius et al., 2018) reported that students tend to question peers' comments and exert more effort into processing them as they do not take the expertise of peers for granted. The deep engagement in peers' comments can lead to reflections that feed rich dialogue between students. Peers also communicate their opinions and explain their understanding using a more accessible language (Nicol \& Macfarlane-Dick, 2006), as opposed to instructors who tend to use an academic writing style in their feedback (MacLellan, 2001). Sharing the same vocabulary can create a common ground for building and maintaining productive dialogue. Moreover, although the quality of feedback from peers cannot always match that of instructors, peer feedback compensates for lower quality by its greater volume, frequency, and immediacy (Topping, 2005). That is, peer feedback can enhance dialogue with diverse and frequent peer interactions (Filius et al., 2018).

Despite its promises, simply replacing instructors with peers and following the same activity design may not yield the expected learning gains from dialogic feedback. Dialogic feedback is translated into a different process when conducted with peers, who are unlikely to 
present the same capacity as instructors in providing high quality feedback and leading a productive dialogue. Therefore, merely providing students with opportunities to talk with their peers about the feedback without explicit guidance, plan, and structure is an optimistic design decision. For example, peers' perspectives about the quality of a student work might differ, which may lead to inconsistent feedback, and in turn, to an unproductive dialogue that may confuse students instead of enhancing their learning (Hounsell et al., 2008). Similarly, without a proper planning, reviewing peers may face difficulty organizing their contributions during the dialogue. Thus, we suggest that theoretically framing dialogic peer feedback is a precursor to its successful design and implementation. In the next section, we present a theoretical framework of collaborative peer feedback. This framework aims to accelerate a shift away from instructor-directed feedback practices toward student-centred approaches and create a wider paradigm change in the teaching practices of higher education.

\section{A Theoretical Framework of Collaborative Peer Feedback}

We present a theoretical framework (see Figure 1) which suggests an ongoing dialogue among the peers (providing feedback) and the student(s) (receiving feedback) through a 3-phase collaborative activity, beginning with the collective planning of the feedback provision by the reviewing peers and continuing until the target students manage to apply the feedback properly to improve their learning and to progress on the task. In particular, this framework structures the dialogue into three interconnected phases: dialogue during (1) the planning and coordination of the feedback activities, (2) the discussion around the feedback to support its uptake, and (3) the translation of the feedback into task engagement. These phases may involve several iterations within themselves. For example, in the first phase, peers may continue their discussion in several rounds to build a consensus on the focus of the feedback. Also, it is noteworthy that these phases are interconnected but not necessarily linear, and they may often 
overlap. For instance, peers may continue the coordination of feedback activities while engaging in discussion around the feedback. Thus, this framework is intended to offer flexibility to be applicable in different contexts.

The presented framework is grounded in Hadwin and colleagues' (2017) framing of collaborative learning which suggests that a successful collaborative activity involves selfregulation of learning (SRL), co-regulation of learning (CoRL), and socially shared regulation of learning (SSRL). Similarly, we suggest that dialogic peer feedback as a collaborative learning activity involves regulation of learning at different levels. In the first phase, peers socially regulate their learning (i.e., SSRL) (Hadwin et al., 2011) to negotiate, plan, and coordinate the feedback activities. In the second phase, during the feedback discussion, CoRL occurs (Hadwin et al., 2010) as peers support the students' regulation of learning. CoRL in this phase helps prepare students' transition toward self-regulation (i.e., the last phase of dialogic feedback) (Hadwin et al., 2011). In the last phase, students self-regulate their learning, i.e., SRL (Winne \& Hadwin, 1998), when translating the feedback received into meaningful task engagement and progress. Based on the feedback literature, particular events at each level of regulation of learning are elaborated for each phase. These phases are explained as follows.

$<$ Figure 1 goes here>

\section{Phase 1: Planning and Coordination of Feedback Activities}

According to the theoretical framework, the peer feedback activity should start with collective planning and coordination of feedback and its provision, and it involves SSRL among peers (Hadwin et al., 2017). The purpose is to construct a shared understanding among (reviewed and reviewing) students regarding the weaknesses of the submitted work (that need to be addressed later through peer feedback). In collaborative activities, having a set of shared goals is a precursor to the success of the group work (Malmberg et al., 2015). Similarly, in dialogic 
peer feedback, initial agreement on the activity goals and plan can later lead to consistent peer engagement (e.g., balanced participation) and coherent feedback that is desired by the reviewed student. Peers' inconsistent feedback may confuse students and harm their learning (Hounsell et al., 2008).

This process of reaching a consensus on the quality of the student work can be facilitated through the use of rubrics. Rubrics help establish a clear communication channel among students (DeCastro-Ambrosetti \& Cho, 2005) and create a shared focus on the important aspects of the student work (Jackson \& Larkin, 2016). Using the rubric, peers should assess the work and then discuss to close any discrepancies between their views. Students' selfassessments should be also incorporated into peers' assessments (Carless et al., 2011), and the students themselves should be encouraged to participate in the discussion to provide their own perspectives. Self-assessment as an element of dialogue for consensus building can later lead to a productive discussion around the feedback provided (in the second phase) and enhance students' internalization and use of peer feedback (in the last phase) (Taras, 2003).

After establishing a common ground, peers should plan the feedback activities by identifying the responsibilities (i.e., the focus of each feedback and the responsible peer to provide it) and set some standards for their engagement levels, such as responding to a student question within a day. This planning is essential for peers to organize and coordinate their collective efforts to achieve the maximum productivity in feedback provision and discussion. After planning their feedback activities, peers should monitor and evaluate their collective activities and make strategic changes in their engagement if they fail to meet the standards they set earlier (Wise \& Vytasek, 2017). That is, this phase does not end with the plan but spans over the discussion phase since peers are likely to continue regulating their collective activities based on their interactions with the target student. 


\section{Phase 2: Discussion around the Feedback to Support Its Uptake}

The framework suggests that the second phase is the one where the core dialogue among peers focusing on the feedback provided takes place. This is the phase where students should put effort to make sense of feedback through discussing with their peers and to derive relevant and concrete actions to take in the later steps. In this phase, according to the plan created in the previous phase, peers provide feedback and engage in a discussion with the target student to support its uptake. This discussion is literally the dialogue component that is regarded as dialogic feedback in the literature (Zhu \& Carless, 2018), but framed as one distinct phase of the whole process in this paper. The proposed framework does not only provide an internal structure for productive discussion of the feedback to support its uptake but also enhances this phase with the addition of planning (i.e., first phase) and action taking phases (i.e., third phase). In this phase, first, the peers should provide the feedback addressing the agreed weaknesses of the student work. Then, the students being reviewed should reflect on each feedback item provided for different aspects of the work and share their own understanding. Reflection as a deep learning strategy can help students understand the feedback (Hatziapostolou \& Paraskakis, 2010) and make connections with their own work (Quinton \& Smallbone, 2010). Some existing frameworks (e.g., Gibbs, 1988) can be used to provide an explicit guidance during the reflection.

During this phase, the quality of the dialogue in terms of constructive feedback and the follow-up discussions is necessary for collective meaning-making (Van Leeuwen et al., 2014). In this regard, the notion of exploratory dialogue proposed by Mercer (2000) provides a sound ground for peers' discussion of the feedback. In exploratory dialogue, students "engage critically but constructively with each other's ideas" (Mercer, 2000, p. 98) and build a shared understanding together while the other types involve exchange of knowledge or results in 
agreement or disagreement without reflecting on others' contributions (ibid). Therefore, exploratory feedback dialogue can indicate that students go beyond superficial discussion of feedback by challenging the peers' feedback and reaching joint decisions based on a shared understanding. Nonetheless, peers' feedback statements seed the dialogue, and therefore the quality of the dialogue is highly dependent on the quality of the peer feedback. Feedback aiming at guiding learning processes (i.e., process level) and the feedback aiming at selfregulatory proficiencies (i.e., self-regulation level) are the most effective for learning (Hattie $\&$ Timperley, 2007). In this phase, we suggest promoting peer feedback at process and selfregulation level and to maximize the exploratory nature of the dialogue seeded by the feedback.

Based on Butler and Winne's (1995) model of SRL, the framework suggests that in the next step students should focus on setting goals based on their interpretations of the feedback and determine the actions to take to achieve these goals. Dialogue with the peers can be essential during this process in helping students translate the given feedback into strategic task engagement (Quinton \& Smallbone, 2010); in other words, to move the feedback forward (Orsmond et al., 2013). Research shows that students who receive specific suggestions from peers on how to use feedback are more likely to make a more strategic use of the feedback (Burke, 2009). Driven by each feedback item separately, dialogue may continue in several parallel threads, and each thread may result in its own goals and action list. In this step, peers' support for students to translate the feedback into an action plan can facilitate CoRL and support students' shift toward SRL later when performing these actions (Hadwin et al., 2010). Students may start working on the settled actions while the dialogue regarding other feedback may still continue. The outcome of this phase consists of the learning goals and actions (per each feedback item) that students agree to perform (in the last phase).

\section{Phase 3: Translation of the Feedback into Task Engagement and Progress}


According the framework, to yield the desired learning benefits, peer feedback should be operationalized by the students by executing the action plan created previously, which constitutes the last phase of the whole feedback process. In this phase, regulation of learning plays a key role during students' efforts to accomplish the learning goals and to progress on their work as planned (Winne \& Hadwin, 1998). In particular, students need to monitor their progress on the actions and make iterative adaptations in their strategies and tactics to improve their task engagement (Butler \& Winne, 1995).

According to the framework, dialogue is also essential while students are working on the planned actions. In this regard, self (for SRL) and peer monitoring (for CoRL) is necessary to trigger relevant dialogue. Students should be enabled and encouraged to track their progress on the actions for monitoring purposes. Through self-monitoring, students can generate internal feedback that helps them interpret and assess their current progress and revise their subsequent engagement (Winne \& Hadwin, 1998). Similarly, peers should be enabled to monitor the target student's ongoing progress on the actions to enable CoRL (Er, 2020). Opportunities should be provided to connect students with reviewing peers and promote the dialogue among them for addressing any difficulties faced while progressing on the action plan and advancing in the work. By engaging in dialogue with their peers, students can receive external feedback (from peers) that may "confirm, add to, or conflict with the learner's internal interpretations of the task and the path of learning" (Butler \& Winne, 1995, p. 248). That is, both internal and external feedback (through self and peer monitoring) is essential in this phase to support students' regulation of their learning while pursuing the feedback-driven learning actions.

The Role of Instructors 
In this student-centred framework, the instructors' role remains essential as the facilitator in all phases of collaborative peer feedback. In the first phase, instructors may act in several ways to support students. For instance, some review groups might have very conflicting perspectives about the quality of the student work being reviewed and face difficulty in reaching a consensus. Instructors should facilitate the discussion among students to identify and address the potential misinterpretations regarding the assessment criteria, student work, or peers' ideas. Instructor support is also essential for the reviewing groups who are not able to formulate a plan for feedback provision, which might be associated with lack of knowledge on the related concept or poor understanding of the assessment criteria (Nilson, 2003). Instructors can help such groups by enhancing their understanding of the associated concept as well as the assessment criteria and by providing concrete examples of feedback (Jonsson, 2013).

In the second phase, instructors can play a significant role in enhancing the feedback dialogue among students, and therefore supporting students' interpretation of feedback and creation of relevant goals and actions. Although discussing the feedback can lead to greater learning gains (Filius et al., 2018), students are not always inclined to do so (Carless, 2016). To increase student motivation, instructors can emphasize mastery learning goals in the class and illuminate the importance of feedback discussion with exemplars (Carless \& Boud, 2018). Instructors can also intervene in specific review groups facing trouble negotiating meaning from feedback. In the third phase, where students translate the feedback into progress, instructor support could be critical in several ways. Students may have difficulty enhancing a particular aspect of their work based on peer feedback. In this regard, instructors can provide supplementary learning material to support students' conceptual understanding of the associated topic (Shahbodin \& Zaman, 2008). Additionally, instructors can offer opportunities 
(e.g., online discussion forums) to connect students with their review peers to ask for help when they cannot manage to act on the feedback provided by the peers.

\section{Design Principles for Collaborative Peer Feedback}

Based on the theoretical framework, seven design principles are derived to guide the implementation of sound dialogic peer feedback practices. The principles P1, P2 and P3 correspond to the first phase; P4 and P5 correspond to the second phase; and P6 and P7 correspond to the third phase in the framework.

P1. Connect self-evaluation with peer evaluations. According to this principle, the feedback activity should involve self-evaluation of the submitted work together with peer evaluations. When given the opportunity to compare with peers' views, students are better able to make sound judgments about the quality of their work (i.e., evaluative judgement) (Boud, Lawson, \& Thompson, 2013). Peers' scoring can serve as an exemplar for students and enable them to make a more accurate judgment of their work against the standards as defined in the assessment criteria (Carless, 2015). Accordingly, research shows that when peer assessments are conducted with self-assessment, students' understanding of the required quality level improves and their subjectivity in their judgements decreases (To \& Panadero, 2019). Evaluative judgment is a critical skill that enhances learning gains from the feedback process (Carless \& Boud, 2018), and if students are given opportunities to practice it, the accuracy of their judgements improves over time (Boud et al., 2013).

P2. Provide opportunities to resolve the discrepancies in students' perspectives about the quality of the work. Connected with the first principle, this second principle suggests that alignment of students' opinions about the quality of the work based on the rubric is a critical process of dialogic peer feedback. This alignment should be not only among 
the reviewing peers but also between the reviewing peers and the student being reviewed. Contradictory peer perspectives may yield inconsistent feedback that is difficult to interpret and to act on for the student (Hounsell et al., 2008). Moreover, seeking a consensus of the students being reviewed on the weaknesses of the work can enhance their acceptance and use of the critical feedback (Taras, 2003). Thus, instructors should provide opportunities for students to align their perspectives regarding the quality of the work to be reviewed.

P3. Provide mechanisms to (collectively) plan the feedback before its provision. This principle suggests that peers should be enabled to collectively plan and organize their feedback before providing it. Planning is necessary to ensure that a) feedback to be provided later will be coherent and systematic, and b) peers' participation in feedback provision will be balanced and adequate. An effective planning requires the alignment of peers' perspectives as suggested by $\mathrm{P} 2$. With an agreement on what is missing or inadequate in the reviewed work, peers can accomplish a shared focus of their feedback and plan their feedback productively. Moreover, peers need to plan their engagement in feedback provision to ensure a fair sharing of responsibility, which is necessary for a successful collaboration (Janssen et al., 2007). They should be encouraged to decide on the task distribution and schedule (e.g., who is providing which feedback and when).

P4. Enable dialogue around the feedback to support its uptake. Dialogue can support students' sense-making from feedback in an interactive way (Carless, 2016; Zhu \& Carless, 2018). This principle suggests that feedback provision should incorporate a dialogue component where students can react to feedback and share their interpretations with peers. Instructors should encourage exploratory dialogue, where students construct a shared understanding of feedback by constructively reflecting on each other's ideas 
(Mercer, 2000). The construction of the dialogue can be guided based on the plan for the feedback provision collectively created by peers (as indicated in P3).

P5. Enable students to set goals and create an action plan with peers based on the feedback.

Dialogue adds value to the feedback process if it enhances students' understanding of feedback (Sutton, 2009) and enables them to set relevant goals toward progressing on their work (Carless \& Boud, 2018). Accordingly, this principle suggests that for students to move forward with the feedback received, they should set relevant learning goals and plan the actions to accomplish these goals. During this process of converting feedback into an action plan, students should maintain a dialogue with peers to receive their input. Peers can help confirm if the goals set are relevant and if the planned actions are adequate considering their actual intentions with the corresponding feedback. Without the support of the feedback provider, students may fail to develop a plan to act on the feedback (Boud \& Molloy, 2016).

P6. Enable students to track, monitor, and evaluate their progress on the learning actions. According to this principle, students should track their progress on learning actions. Consistent tracking will generate a complete history of the whole progress across all actions, which then can be used to enable students to monitor how much they advanced over time and evaluate their status against the goals set initially (Butler \& Winne, 1995). By self-evaluation, students can decide if they need to update their current strategies and tactics to improve their engagement on the task so that they are closer to achieving the learning goals (Winne \& Hadwin, 1998).

P7. Enable dialogue with peers while students are revising their work. This principle suggests that students should be enabled to receive their peers' input about their ongoing progress while revising their work to pursue the learning goals. Students' 
tracking of their progress over time (as indicated in P6) can inform the peers regarding the current progress on different tasks, and in this way, peers can identify the guidance necessary to enhance students' engagement (i.e., co-regulate). In this regard, peer feedback can enhance students' own interpretation of their progress (thus, complementing the internal feedback) and lead to a better regulation of learning (Butler \& Winne, 1995).

Although the application of all seven principles is desired to inform the design of a feedback activity, the inclusion of all may introduce not only a sudden significant change in the existing practices of instructors but also a significant workload on students in real-world practice, which may risk the success of the peer feedback activity. Therefore, we recommend a careful initial selection and application of these principles depending on the contextual factors and constraints (e.g., course timeline, other learning activities, etc.), and continuing with a gradual application of all after successful earlier practices with the core principles. We argue that the principles P2, P4, and P5 build the backbone of the framework, and therefore are relatively more vital. The reviewing peers (if possible, with the participation of the target students) should align their perspectives about what they consider missing or incomplete in the student work being reviewed. According to $\mathrm{P} 2$, this is precursor to the provision of consistent and high-quality feedback. Second, based on P4, the target students should be enabled to talk to their peers about feedback to enhance their understanding of what the feedback is actually saying. This dialogue about feedback is key to moving the feedback forward (Orsmond et al., 2013). Last, as suggested in P5, closely connected with P4, students should set goals and make an action plan based on their understanding of each feedback comment. Such an effort will not only verify the correct interpretation of feedback but also motivate them to put the feedback into action based on a plan. 
The other principles complement these three and the practitioners should always consider applying them when designing peer feedback activities. The application of all principles is illustrated through an example scenario as follows.

\section{Example Scenario: Applying the Principles to Design a Feedback Activity in a Blended Science Class}

This imaginary scenario is provided solely to illustrate the application of the design principles in implementing a practice of dialogic peer feedback in a blended science class in higher education. In this scenario, students already wrote a lab report about a recent experiment that they conducted individually. The course instructor decides to implement a peer review activity in which two random (student) reviewers are assigned to each peer work submitted and provide feedback to help their peers improve their reports before the final submission. The design principles can be applied to implement this peer review task as a dialogic feedback activity.

First, according to P1, each submitted work needs to be first assessed by the students (i.e., peer- and self-assessment). To facilitate this process online, the instructor creates an online form (based on the assessment rubric). In the next face-to-face class meeting, as suggested by P2, the instructor allows students to sit together with their peers assessing their work to compare the assessment scores and to identify the reasons for the discrepancies in the scores (if any). They should discuss together to align their perspectives about the quality of the work and ask for instructor help if they face difficulties reaching a consensus. After students agree about the qualities of the work at hand, P3 recommends that the reviewing peers should create a plan for the feedback provision. For this purpose, they can use a paper (or an Excel document) to take notes about the focus of the feedback (e.g., improving the presentation of the results) and decide on who is responsible for providing that feedback. These notes serve as 
a blueprint of the planned feedback provision, which can be also shared with the target student whose work is being assessed.

P4 suggests an ongoing dialogue about the feedback provided. Accordingly, for the next task, the instructor can use a collaborative space, such as Google Documents, to allow peers to collaboratively post their (feedback) comments on the assigned work based on the feedback plan created previously. At the same time, students receiving the feedback can reply back to the comments to reflect and share their understanding. After the feedback provision and dialogue, in the next class meeting, according to P5, students work together with their peers to set goals and create an action plan, that is, the list of actions that they will take to improve their work based on the feedback received. A common Google Spreadsheet can be created to note these goals and actions, where the target students can record the progress on each action based on the revisions incorporated, as recommended in P6. This spreadsheet can also enable the students to monitor and evaluate their progress. According to $\mathrm{P} 7$, the instructor should provide students with opportunities for discussing the progress made with the peers. In a following class meeting, the instructor should allow students to discuss the current progress with their peers and ask for their help if needed. The common Google Spreadsheet where the progress is tracked can be used by peers to facilitate the discussion.

Please note that in this scenario, each of these processes was planned for a single iteration. However, depending on the contextual needs, instructors can run several iterations for any of these tasks (e.g., discussing the progress, aligning the perspectives).

\section{Discussion}

The presented framework proposes a learner-centred approach, which aligns closely with existing feedback models and follows the principles of good feedback practices (Nicol \& Macfarlane-Dick, 2006; Carless et al., 2011; Boud \& Molloy, 2016). In the framework, 
students are placed as learning agents who negotiate meaning from feedback through a dialogue with peers, which is a recommended practice in the recent literature ( Boud \& Molloy, 2016; Zhu \& Carless, 2018). Moreover, a good feedback practice should enable students to take actions to reduce the gap between current and desired performance (Nicol \& MacfarlaneDick, 2006). Rooted in co-regulation of learning and self-regulation of learning, the framework delineates the necessary processes to move from feedback dialogue to concrete actions to close the gap based on predetermined goals. In particular, the framework has connections with Butler and Winne's (1995) model of self-regulated learning to theorize the shift from feedback dialogue to concrete learning actions and to justify the importance of peer feedback in enhancing self-regulation while students are performing the actions.

This framework can be used in conjunction with other models and frameworks to achieve more rigour in the integration of dialogic peer feedback into higher education curriculums. One framework in this regard is the feedback triangle, proposed by Yang and Carless (2013), which suggests three dimensions for effective feedback implementation: cognitive, social-affective, and structural dimensions. Considering these dimensions, dialogic peer feedback can be designed and enacted more effectively if (1) there is a focus on enhancing students' capacities to solve discipline-specific problems (i.e., cognitive dimension), (2) there is a trusting atmosphere that promotes students' positive learning dispositions to make productive use of feedback (i.e., social-affective dimension), and (3) there is a supportive institutional environment for innovative assessment policies such as allowing multi-stage assignments (i.e., structural dimension). These dimensions can help take into account other factors framing and shaping pedagogies and practices in higher education, thus facilitating a seamless integration of dialogic peer feedback based on the design principles presented. 
Feedback literacy, defined as "the understandings, capacities and dispositions needed to make sense of information and use it to enhance work or learning strategies" (Carless \& Boud, 2018, p. 2), is considered an essential skill for achievement in higher education. The proposed framework can inform the design of feedback practices in a way that promotes students' feedback literacy skills. Features of student feedback literacy includes appreciating feedback, making judgements, managing affect, and taking action (Carless \& Boud, 2018). First, the theoretical framework guides students' active participation starting from negotiating the qualities of the work until peer feedback results in improvements based on the goals and actions determined by the students (i.e., appreciating feedback). Second, the framework has a direct effect on students' judgement skills, which is a required ability from feedback literate students. In particular, the first two principles focus on developing students' capacities to perform accurate judgements through the self-assessment, peer-assessment, and the discussion of the results. Next, constructive dialogue based on (critical) feedback where students actively elicit meaning and specific suggestions is a core component of the framework (i.e., managing affect). Last, the framework includes two phases where students together with the reviewing peers set goals based on feedback and create an action plan (i.e., taking actions). Thus, the proposed framework can help increase the potential of feedback practices in enhancing student feedback literacy.

This framework proposes a student-centred approach to dialogic peer feedback which requires students' active engagement in multiple learning processes. Although such engagement can yield significant learning gains, it is a challenge to maintain students' motivation to actively attend to all the tasks suggested in the framework. One approach to promote student engagement might be to acknowledge student efforts by assigning a portion of course grade (e.g., 10 over 100) for the peer feedback activity. Previous research noted 
positive effects of grading on student engagement (Widiastuti, 2017). As another strategy, training of students about the feedback activity accompanied with a guided example practice can promote students' active participation in all feedback activities (Filius et al., 2018).

\section{Conclusions and Future Work}

A theoretical framework of collaborative peer feedback is presented to support creating rigorous feedback practices in higher education that enrich students' learning gains through planned and actionable feedback dialogue. In this framework, dialogic peer feedback is conceptualized as a collaborative activity consisting of three phases. The framework outlines for each phase the tasks to be performed individually or collaboratively by reviewing and reviewed students. Design principles to apply this framework in practice are presented to offer an explicit guidance for practitioners to help enhance their current feedback practices with dialogue. The application of these principles is presented through an example to provide a more accessible illustration for practitioners.

We propose several lines of future research to expand on the potential of the framework. First, the framework needs to be applied in a real-world context to test its validity. The design principles can be used to design a real-word feedback practice, where students' behaviours and learning experiences can be analysed to collect evidence regarding how engagement in the tasks and processes (proposed in the framework) affect the feedback quality, feedback use, progress on the work at hand, and overall satisfaction. In this regard, our plan is first to apply and evaluate this model in smaller scales, where class size is preferably less than 30 , and move to larger scales gradually after collecting strong evidence on the effectiveness of the theoretical framework. Our intention is to conduct studies in different domains to test the generalizability of the proposed framework. The scalability of the framework can be also enhanced with technological support. We have applied the proposed design principles in the design of a web- 
based platform, called Synergy (Er et al., 2019), to help facilitate the dialogic feedback activity among students. Digital technologies can offer certain advantages in creating effective dialogic feedback practices (e.g., reflective interaction) (Carless et al., 2011). Thus, another future work is to design interventions with Synergy and evaluate its effectiveness in facilitating dialogic feedback based on the design principles. Last, as highlighted in the framework, an instructor's facilitation plays a critical role in dialogic peer feedback (Zhu \& Carless, 2018). However, the instructor can offer very limited support if the dialogic feedback is conducted among large learning cohorts. Learning analytics (Gašević et al., 2015) can be used to empower instructors to intervene as necessary based on actionable insights derived from student engagement data. In our ongoing work, we have incorporated learning analytics support for instructors into Synergy to support their class-wide monitoring of student activities during peer feedback activity (Er et al., 2020). We will conduct several evaluation studies to measure the capacity of this analytics support in terms of helping instructors intervene in a timely manner to enhance students' learning experiences.

\section{Acknowledgments}

This research of the first author has been fully funded by the European Union's Horizon 2020 research and innovation programme under the Marie Sklodowska-Curie grant agreement 793317. The research of the second author is partially funded by the European Regional Development Fund and the National Research Agency of the Spanish Ministry of Science, Innovations and Universities under project grants TIN2017-85179-C3-2-R, by the European Regional Development Fund and the Regional Council of Education of Castile and Leon under project grant VA257P18, and by the European Commission under project grant 588438-EPP1-2017-1-EL-EPPKA2-KA.

\section{References}


Ajjawi, R., \& Boud, D. (2017). Researching feedback dialogue: An interactional analysis approach. Assessment and Evaluation in Higher Education, 42(2), 252-265. https://doi.org/10.1080/02602938.2015.1102863

Ajjawi, R., \& Boud, D. (2018). Examining the nature and effects of feedback dialogue. Assessment and Evaluation in Higher Education, 43(7), 1106-1119. https://doi.org/10.1080/02602938.2018.1434128

Askew, S., \& Lodge, C. (2000). Gifts, ping-pong and loops -Linking feedback and learning. In S. Askew (Ed.), Feedback for learning (pp. 1-17). Routledge.

Bloxham, S., \& Campbell, L. (2010). Generating dialogue in assessment feedback: Exploring the use of interactive cover sheets. Assessment \& Evaluation in Higher Education, 35(3), 291-300. https://doi.org/10.1080/02602931003650045

Boud, D., Lawson, R., \& Thompson, D. (2013). Does student engagement in self-assessment calibrate their judgement over time? Assessment \& Evaluation in Higher Education, 38(8), 941-956.

Boud, D., \& Molloy, E. (2016). Rethinking models of feedback for learning: The challenge of design. Assessment \& Evaluation in Higher Education, 38(6), 698-712. https://doi.org/10.1080/02602938.2012.691462

Burke, D. (2009). Strategies for using feedback students bring to higher education. Assessment \& Evaluation in Higher Education, 34(1), 41-50. https://doi.org/10.1080/02602930801895711

Butler, D. L., \& Winne, P. H. . (1995). Feedback and self-regulated learning: A theoretical synthesis. Review of Educational Research, 65(3), 245-281.

Carless, D. (2013). Trust and its role in facilitating dialogic feedback. In D. Boud \& L. Molly (Eds.), Feedback in higher and professional education (pp. 90-103). Routledge. 
Carless, D. (2015). Excellence in University Assessment: Learning from award-winning practice. Routledge.

Carless, D. (2016). Feedback as dialogue. In M. Peters (Ed.), Encyclopedia of Educational Philosophy and Theory (pp. 1-6). Springer. https://doi.org/10.1007/978-981-287-532-7

Carless, D., \& Boud, D. (2018). The development of student feedback literacy: Enabling uptake of feedback. Assessment \& Evaluation in Higher Education, 43(8), 1315-1325. https://doi.org/10.1080/02602938.2018.1463354

Carless, D., Salter, D., Yang, M., \& Lam, J. (2011). Developing sustainable feedback practices. Studies in Higher Education, 36(4), 395-407. https://doi.org/10.1080/03075071003642449

DeCastro-Ambrosetti, D., \& Cho, G. (2005). Synergism in learning: A critical reflection of authentic assessment. The High School Journal, 89(1), 57-62.

Ellegaard, M., Damsgaard, L., Bruun, J., \& Johannsen, B. F. (2017). Patterns in the form of formative feedback and student response. Assessment \& Evaluation in Higher Education, 2938(November), 1-18. https://doi.org/10.1080/02602938.2017.1403564

Er, E. (2020). Self and peer monitoring during peer feedback: The instructor perspective. Learning Analytics Summer Institute, 1-8.

Er, E., Dimitriadis, Y., \& Gasevic, D. (2020). Collaborative peer feedback and learning analytics: Theory-oriented design for supporting class-wide interventions. Assessment \& Evaluation in Higher Education, In Press.

https://doi.org/10.1080/02602938.2020.1764490

Er, E., Dimitriadis, Y., \& Gašević, D. (2019). Synergy: A Web-Based Tool to Facilitate Dialogic Peer Feedback. 14th European Conference on Technology Enhanced Learning, EC-TEL 2019, 709-713. 
Ertmer, P. A., Richardson, J. C., Belland, B., Camin, D., Connolly, P., Coulthard, G., Lei, K., \& Mong, C. (2007). Using peer feedback to enhance the quality of student online postings: An exploratory study. Journal of Computer-Mediated Communication, 12(2), 412-433. https://doi.org/10.1111/j.1083-6101.2007.00331.x

Filius, R. M., de Kleijn, R. A. M., Uijl, S. G., Prins, F. J., van Rijen, H. V. M., \& Grobbee, D. E. (2018). Strengthening dialogic peer feedback aiming for deep learning in SPOCs. Computers \& Education, 125, 86-100. https://doi.org/10.1016/j.compedu.2018.06.004

Gašević, D., Dawson, S., \& Siemens, G. (2015). Let's not forget: Learning analytics are about learning. TechTrends, 59(1), 64-71. https://doi.org/10.1007/s11528-014-0822-x

Geitz, G., Brinke, D. J., \& Kirschner, P. A. (2015). Goal orientation, deep learning, and sustainable feedback in higher business education. Journal of Teaching in International Business, 26, 273-292. https://doi.org/10.1080/08975930.2015.1128375

Gibbs, G. (1988). Learning by Doing: A Guide to Teaching and Learning Methods. Further Education Unit.

Gikandi, J. oyc. W., \& Morrow, D. (2015). Designing and implementing peer formative feedback within online learning environments. Technology, Pedagogy and Education, 25(2), 153-170. https://doi.org/10.1080/1475939X.2015.1058853

Hadwin, A. F., Järvelä, S., \& Miller, M. (2011). Self-regulated, co-regulated, and socially shared regulation of learning. In B. J. Zimmerman \& D. H. Schunk (Eds.), Educational psychology handbook series. Handbook of self-regulation of learning and performance (pp. 65-84). Routledge/Taylor \& Francis Group.

Hadwin, A. F., Järvelä, S., \& Miller, M. (2017). Self-regulation, co-regulation and shared regulation in collaborative learning environments. In D. H. Schunk \& J. Greene (Eds.), Handbook of self-regulation of learning and performance (2nd ed.). Routledge. 
Hadwin, A. F., Oshige, M., Gress, C. L. Z., \& Winne, P. H. (2010). Innovative ways for using gStudy to orchestrate and research social aspects of self-regulated learning. Computers in Human Behavior, 26(5), 794-805. https://doi.org/10.1016/j.chb.2007.06.007

Hamer, J., Purchase, H., Luxton-Reilly, A., \& Denny, P. (2015). A comparison of peer and tutor feedback. Assessment and Evaluation in Higher Education, 40(1), 151-164. https://doi.org/10.1080/02602938.2014.893418

Hattie, J. (1999). Influences on student learning. http://geoffpetty.com/wpcontent/uploads/2012/12/Influencesonstudent2C683.pdf

Hattie, J., \& Timperley, H. (2007). The power of feedback. Review of Educational Research, 77(1), 81-112. https://doi.org/10.3102/003465430298487

Hatziapostolou, T., \& Paraskakis, I. (2010). Enhancing the impact of formative feedback on student learning through an online feedback system. Electronic Journal of E-Learning, $8(2), 111-122$.

Holmes, K., \& Papageorgiou, G. (2009). Good, bad and insufficient: students' expectations, perceptions and uses of feedback. Journal of Hospitality, Leisure, Sport and Tourism Education, 8(1), 85-96.

Hounsell, D., Mccune, V., Hounsell, J., \& Litjens, J. (2008). The quality of guidance and feedback to students. Higher Education Research \& Development, 27(1), 55-67. https://doi.org/10.1080/07294360701658765

Jackson, C. W., \& Larkin, M. J. (2016). Teaching students to use grading rubrics. Teaching Exceptional Children, 35(1), 40-45. https://doi.org/10.1177/004005990203500106 Janssen, J., Erkens, G., Kanselaar, G., \& Jaspers, J. (2007). Visualization of participation: Does it contribute to successful computer-supported collaborative learning? Computers 
\& Education, 49(4), 1037-1065. https://doi.org/10.1016/j.compedu.2006.01.004

Jonsson, A. (2013). Facilitating productive use of feedback in higher education. Active Learning in Higher Education, 14(1), 63 -76.

https://doi.org/10.1177/1469787412467125

MacLellan, E. (2001). Assessment for learning: The differing perceptions of tutors and students. Assessment \& Evaluation in Higher Education, 26(4), 307-318.

Malmberg, J., Järvelä, S., Järvenoja, H., \& Panadero, E. (2015). Promoting socially shared regulation of learning in CSCL: Progress of socially shared regulation among high- and low-performing groups. Computers in Human Behavior, 52, 562-572. https://doi.org/10.1016/j.chb.2015.03.082

Mercer, N. (2000). Words and Minds: How We Use Language to Think Together. Routledge.

Nicol, D. (2010). From monologue to dialogue: Improving written feedback processes in mass higher education. Assessment \& Evaluation in Higher Education, 35(5), 501-517. https://doi.org/10.1080/02602931003786559

Nicol, D., \& Macfarlane-Dick, D. (2006). Formative assessment and self- regulated learning: A model and seven principles of good feedback practice. Studies in Higher Education, 31(2), 199-218. https://doi.org/10.1080/03075070600572090

Nilson, L. B. (2003). Improving student peer feedback. College Teaching, 51(1), 34-38.

O’Donovan, B. O., Rust, C., \& Price, M. (2015). A scholarly approach to solving the feedback dilemma in practice. Assessment \& Evaluation in Higher Education, 41(6), 938-949. https://doi.org/10.1080/02602938.2015.1052774

Orsmond, P., Maw, S. J., Park, J. R., \& Crook, A. C. (2013). Moving feedback forward: Theory to practice. Assessment \& Evaluation in Higher Education, 38(2), 240-252.

Quinton, S., \& Smallbone, T. (2010). Feeding forward: Using feedback to promote student 
reflection and learning - a teaching model. Innovations in Education and Teaching International, 47(1), 125-135. https://doi.org/10.1080/14703290903525911

Sadler, D. R. (1989). Formative assessment and the design of instructional systems. Instructional Science, 18(2), 119-144.

Shahbodin, F., \& Zaman, H. B. (2008). Evaluating the effectiveness problem based learning in science teaching: Hybrid approach. Proceedings of 2018 International Symposium on Information Technology., 1-7.

Shi, M. (2019). The effects of class size and instructional technology on student learning performance. The International Journal of Management Education, 17(1), 130-138. https://doi.org/https://doi.org/10.1016/j.ijme.2019.01.004

Stahl, G., Koschmann, T., \& Suthers, D. (2006). Computer-supported collaborative learning: An historical perspective. In R. K. Sawyer (Ed.), Cambridge handbook of the learning sciences (pp. 409-426). Cambridge University Press.

Steen-Utheim, A., \& Wittek, A. L. (2017). Dialogic feedback and potentialities for student learning. Learning, Culture and Social Interaction, 15(December 2016), 18-30. https://doi.org/10.1016/j.lcsi.2017.06.002

Sutton, P., \& Gill., W. (2010). Engaging feedback: Meaning, identity and power. Practitioner Research in Higher Education, 41(1), 3-13.

Sutton, Paul. (2009). Towards dialogic feedback. Critical and Reflective Practice in Education, 1(1), 1-10.

Taras, M. (2003). To feedback or not to feedback in student self-assessment. Assessment \& Evaluation in Higher Education, 28(5), 549-565.

To, J., \& Panadero, E. (2019). Peer assessment effects on the self-assessment process of firstyear undergraduates. Assessment \& Evaluation in Higher Education, 44(6), 920-932. 
Topping, K. J. (2005). Trends in peer learning. Educational Psychology, 25(6), 631-645. https://doi.org/10.1080/01443410500345172

Urquhart, L. M., Rees, C. E., \& Ker, J. S. (2014). Making sense of feedback experiences: A multi-school study of medical students' narratives. Medical Education, 48(2), 189-203.

Van Leeuwen, A., Janssen, J., Erkens, G., \& Brekelmans, M. (2014). Supporting teachers in guiding collaborating students: Effects of learning analytics in CSCL. Computers \& Education, 79, 28-39. https://doi.org/10.1016/j.compedu.2014.07.007

Widiastuti, I. A. (2017). Teachers' classroom assessment and grading practices. Global Conference on Teaching, Assessment, and Learning in Education (GC-TALE 2017), 17.

Winne, P. H., \& Hadwin, A. F. (1998). Studying as self-regulated learning. In D. J. Hacker, J. Dunlosky, \& A. C. Graesse (Eds.), Metacognition in educational theory and practice (pp. 277-304). Lawrence Erlbaum Associates Publishers.

Wise, A. F., \& Vytasek, J. (2017). Learning analytics implementation design. In C. Lang, G. Siemens, A. Wise, \& D. Gašević (Eds.), Handbook of Learning Analytics (pp. 151-160). Society for Learning Analytics Research. https://doi.org/10.18608/hla17.013

Wright, G. B. (2011). Student-centered learning in higher education. International Journal of Teaching and Learning in Higher Education, 23(3), 92-97.

Yang, M., \& Carless, D. (2013). The feedback triangle and the enhancement of dialogic feedback processes. Teaching in Higher Education, 18(3), 285-297.

Zhu, Q., \& Carless, D. (2018). Dialogue within peer feedback processes: Clarification and negotiation of meaning. Higher Education Research \& Development, 37(4), 883-897. https://doi.org/10.1080/07294360.2018.1446417 